\title{
Humor in the Academic Library: You Must Be Joking! or, How Many Academic Librarians Does It Take to Change a Lightbulb?
}

\section{Leah Black and Denise Forro}

In an effort to improve profits and productivity for employers and the quality of work life for employees, many U.S. companies have begun to embrace humor in the workplace. Humor is thought to be a means to promote teamwork, reduce stress, stimulate creativity, and improve communication, morale, and productivity. Initiatives in business have included official programs such as creation of "humor rooms" for employee use as well as less-structured mechanisms such as encouraging the use of humor in memos and staff newsletters. This investigation discusses appropriate and potentially helpful applications of workplace humor to enhance the work atmosphere in academic libraries.

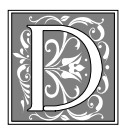

ownsizing, limited monetary rewards, added responsibilities, and constant exhortation to "do more with less" has resulted in a disgruntled, dissatisfied, dismal, and disease-prone workforce. As society increasingly values leisure, equating leisure (play) with fun and work with drudgery, today's workers are actively seeking ways to make work more enjoyable and the workplace more humane. The benefits of humor on the psychological and physiological well-being of workers has been the subject of study for many years and recently has earned the attention of management and human resource offices across the country.

Humor can be defined in many different ways. In a standard dictionary, humor is defined as "that quality in a happening, an action, a situation, or an expression of ideas which appeals to a sense of the ludicrous or absurdly incongruous: comic or amusing quality." ${ }^{1}$ Applied in the workplace, humor is viewed as a means to promote teamwork, reduce stress, stimulate creativity, and improve communication, morale, and productivity.

Humor also can be a tool to enhance personal well-being. It does not necessarily need to flow from management to staff but can be embraced on a personal level. Health professionals suggest that maintaining a sense of humor can reduce personal stress and lower blood pressure, changes that can be measured in physiological and psychological terms. ${ }^{2,3}$ 
The many serious articles and books about humor in the workplace prompted an examination of the application of humor in academic libraries. Academic institutions generally do not enjoy reputations as breeding grounds for humor, and the libraries associated with these institutions tend to reflect the institutions they serve. So, in what ways can the use of humor help an academic library effectively fulfill its mission?

\section{Overview of Humor Literature and Internet Sites}

To begin answering this question, published materials and Internet sites on various aspects of the topic were identified. Although this was not an extensive literature review, the authors perused a variety of articles and sites representing current perspectives in the fields of library science, business, psychology, education, and social sciences, focusing on both individual concerns and present applications in the workplace.

The correlation between humor and creativity has been investigated by a number of researchers. In one study, researchers administered both creativity and humor measures to eighty-six mental health professionals and found a "significant and positive" relationship between humor and creativity scores. The study concluded that humor and creativity are related "in that both involve some risk-taking and the production of unexpected and unusual responses." ${ }^{4}$

Research into the physical and psychological benefits of humor is fairly recent, though it generally is believed that a positive relationship exists. The experiences of Norman Cousins in the late 1970s popularized the belief that laughter promotes healing and helps people deal with life's adversities. One researcher notes, however, that much of the evidence cited to date linking humor with good health and psychological well-being is anecdotal and that more empirical study is needed. ${ }^{5}$ Humor is free and available to anyone, so it is important to know the effects of humor and the extent to which it can help people deal with sickness and stress. Developing a sense of humor and actively incorporating humor into daily life "has at least one major advantage over most other coping mechanisms: It is fun." 6

\section{The correlation between humor and creativity has been investigated by a number of researchers.}

In an effort to improve working conditions and increase profits, many corporations are hiring humor consultants (The HUMOR Project, Funny Business, C.W. Metcalf \& Co., and Playfair, to name a few) and instituting a variety of humorrelated programs in the workplace. Reported advantages to such programs include enhanced creativity, team spirit, motivation and morale, happier working relationships, increased productivity, better communication among workers, less absenteeism and stress, and better marketing. ${ }^{7}$ Humor helps employees adapt to and cope with change, and can better enable them to make their feelings and needs known to upper management. ${ }^{8}$

Humor consultants stress that humor is a learned response, not something a person automatically possesses. According to consultant C.W. Metcalf, the humor skills required include "the ability to see the absurdity in difficult situations, the ability to take yourself lightly while taking your work seriously, and a disciplined sense of joy in being alive." ${ }^{\prime 9}$ When applied in a workplace setting, a key concept to constructive humor applications is that of recognizing and acknowledging the difference between "childlike" and "childish" behavior. Joel Goodman of the HUMOR Project explains that "childlike behavior can lead to more creative thoughts and actions [whereas] childish behavior can become an interference to the productivity of the workplace."10

Dealing effectively with what one humor professional terms maladaptive stress and terminal professionalism are important goals of humor initiatives in 
business. Maladaptive stress is an "inability to cope with change," whereas terminal professionalism (TP) may be defined in terms of a work atmosphere that embraces stress and overwork, resulting in massive worker burnout; TP is "the selffulfilling prophecy in the expression 'dead serious."'11 In Japan, the term Karoshi is applied to a "condition in which psychologically unsound work processes are allowed to continue in a way that disrupts the worker's normal work and life rhythms, leading to a buildup of fatigue in the body and a chronic condition of overwork accompanied by a worsening of preexisting high blood pressure and hardening of the arteries, finally resulting in a fatal breakdown."12

Humor consultants have worked with major companies such as Manville, Herman Miller, Hewlett-Packard, Wells Fargo, AT\&T, Dupont, Kodak, IBM, and Ben \& Jerry's. Applications of the concepts learned have been varied and creative, from simply incorporating humorous items in a company newsletter to establishing "humor rooms" for employees to use when feeling especially stressed. Humor programs can be especially successful when initiated from senior executives downward in an organization. At Southwest Airlines, one of the most profitable airlines in the United States, CEO Herbert Kelleher actively participates in humor initiatives, including reportedly arriving at a company maintenance hanger in the middle of the night in an outrageous costume.

But humor can also have a negative effect in the workplace. Sarcastic or sexual humor, humor used as a "power play" or to challenge authority, humor employed as a means of excluding others, or humor that is used to undermine, belittle, or humiliate an individual is not appropriate. In addition, efforts to define what is acceptable and what is not can be frustrating, time- consuming, and futile. Humor, like justice and fair play, cannot be legislated.

In addition to the information available in traditional print sources, the Internet offers a smorgasbord of humor-related sites. Searching the Internet with any of the various search engines will locate a multitude of sites. As is true regarding all Internet searching, inappropriate and offensive humor sites will be found, and the addresses may change without advance notice.

\section{Humor programs can be especially successful when initiated from senior executives downward in an organization.}

Several categories of Internet humor information were identified. The first category represents the educational or training aspects of using humor in one's life and work. The HUMOR Project's Web site (http:/ / www.humorproject.com/) includes humorous selections, articles, conference information, and a speaker's bureau. The intent is not only to bring laughter to the workplace, but also to educate employers and employees in the benefits of humor. A similar site, HumorMatters (http://www.humormatters.com/) also seeks to entertain, inform, and educate. There are associations dedicated to the advancement of humor as therapy, as evidenced by the Web site for the American Association for Therapeutic Humor (http://ideanurse.com/aath/). In addition to large organizations, a number of individual consultants were located.

Next are humorous and entertaining sites that do not target a specific segment of the Internet community. These pages can be gleaned for jokes, cartoons, and stories that may help to enliven staff newsletters, memos, and bulletin boards. An interesting site that combines visual effects (using JAVA) and audio clips is The Funny Pages! "Welcome to HA" (http:/ / www.bonk.com/). This site offers a "joke of the day," its own search engine that may be used to find specific jokes, and a substantial archive that may be viewed in reverse chronological order. A similar page is Funny Town (http://www. funnytown.com), which consists of different types of jokes, stories, and quota- 
tions, and requests for additional material. Pages such as The Borderline by Gabe Martin (http:/ / www.the-borderline.com/) offer free cartoons. Many other humorous and fun pages are available.

Some sites cater to a particular profession or career. To assist health professionals in incorporating humor into the workplace, various groups and individuals have placed humor pages on the Web. The Journal of Nursing Jocularity (http:/ / www.jocularity.com/) is a fine example of Web humor for the medical professional. As is true with many Internet humor-related sites, those visiting sites targeted to health professionals must keep in mind the intended audience. The humor is derived from common experiences in medicine and directed toward health workers in particular; those from outside the field may not understand the humor and, in fact, may find the stories and jokes somewhat offensive. Similarly, the Lipstick Librarian (http://www.teleport. com/ petlin/liplib/) is intended for those in librarianship, and the jokes may not be of interest or appear humorous to individuals who do not work in libraries.

\section{Celebrating special theme days can promote fun in the workplace, especially in areas staffed largely by student assistants.}

Finally, specific cartoon characters live not only in the newspapers but also animate the Web. For example, that old curmudgeon feline, Garfield, can be found at http://www.garfield.com/. Visitors may view current comic strips and purchase the latest in Garfield paraphernalia at this site. The Dilbert Zone (http:// www.unitedmedia.com/comics/dilbert/) offers humor in the same vein, though the humor is directed toward the workplace environment-a perfect combination of humor and the workplace and, naturally, a popular site. As is the case with the Garfield site, souvenirs are available for purchase, so a visitor may enjoy a chuckle and purchase a T-shirt from the same Web site. Although the Internet manifests some offensive and distasteful elements, it is nonetheless a valuable mechanism for finding and sharing humor in the workplace.

Although humorous articles on libraries and librarians occasionally appear in the library literature and on the Internet through sites such as the Lipstick Librarian, humor initiatives in academic libraries have not been widely reported. The experiences reported by Susan M. Vazakas and Susan B. Whyte are exceptions. Vazakas describes the methods she employs to lighten the atmosphere in her workplace. Whyte uses humor as "a wonderful vehicle for transferring information painlessly."13 However, in a bibliography appearing in a 1994 issue of the Unabashed Librarian, compiler Roberta L. Tipton notes that "the most appalling part of preparing this bibliography was the dearth of solid, recent articles on humor [in] library management."14

A common thread identified in the printed literature and Internet sites was the use of services offered by humor consultants and other formal training programs. Investigation of training was identified as the logical next step, so arrangements were made for the authors to attend the 12th International Conference on the Positive Power of Humor and Creativity.

\section{The Humor Conference}

Sponsored by the Humor Project, the conference was held in Saratoga Springs, New York, on April 18-20, 1997. The project's goal was "to provide services, programs, and resources that improve the effectiveness and quality of life of individuals, groups and organizations." In addition to the conference, services included a speaker's bureau and a source for books, tapes, videos, kits, and programs geared toward incorporating the power of humor and creativity in life and work. Conference attendees included representatives from many nationally known corporations as well as health care and education professionals.

The conference featured four keynote 
presentations, entertainment by a musical satire troupe, and four opportunities to participate in smaller, formal group sessions on specific topics. During those times when formal presentations were not scheduled, attendees had the opportunity to sample a variety of humor and creativity "potpourri" —an exhibit hall complete with the HUMOResources bookstore; special showings of videos; Tai Chi exercise sessions; clowns, jugglers, puppeteers, and magicians mingling with the crowd; and a special "6 in 60" event in which six conference participants shared their work with humor in ten-minute presentations.

Attending the conference proved beneficial in that it provided firsthand exposure to the ideas of the experts in the field. Using humor to lead a more productive and creative life is dependent upon an individual's capacity for identifying and focusing on the humorous aspects of everyday life. Physical and mental health benefits for the individual may be realized through the development and implementation of a personal action plan grounded in the commitment to maintaining a positive perspective. The idea that people take themselves too seriously was a common theme, with this habit highlighted as a significant cause of personal stress.

Incorporating humor into the workplace requires sensitivity to different individual personality types and corporate cultures, and an understanding that humor is not a one-size-fits-all prescription for success. Understanding the causes of stress and the mechanics of positive stress management is an important element in improving personal relationships, strengthening teamwork, and enhancing one's ability to deal with difficult situations and difficult people.

\section{Humor in Academic Libraries}

How can these philosophies and tactics be applied in an academic library environment? The serious nature of academic research, teaching, and dissemination of knowledge does not typically produce an atmosphere of jocularity; academic libraries, as a part of the larger academic community, naturally reflect this serious atmosphere. However, libraries can and should reap the benefits of supporting humor in the workplace-better interpersonal communication, improved teamwork, and enhanced personal job satisfaction-while acknowledging the serious and vital nature of the services they provide.

\section{Applications for Management}

From a management perspective, some of the most effective humor initiatives may well be the simplest. Creating a humor wall or bulletin board with appropriate cartoons and posted quotes can add a lighthearted touch to a work area. Celebrating special theme days can promote fun in the workplace, especially in areas staffed largely by student assistants. Special themes might include a favorite Tshirt or Hawaiian shirt day, a funny hat day, or a political button day. A library staff lounge humor resource section could be a haven for the irreverent.

Games and contests can be effective ways to encourage staff participation and interaction. At the Michigan State University Libraries, the biennial staff tea was the occasion for a contest in which staff matched baby pictures of colleagues with current photos. A prize was awarded to the person who made the most correct guesses. On another occasion, a murder mystery game was developed in conjunction with the libraries' technical services reorganization planning to encourage staff to work together in teams. Supported by library management, a planning committee selected a "victim" (a staff member), a "weapon" (a card catalog drawer rod), the scene of the "crime" (a workroom in technical services), a "murderer" (another staff member), and a series of clues. To uncover clues, staff were required to use standard library reference tools and library utilities such as OCLC. Participation was voluntary. "Some staff chose not to participate," commented Sue Ward, the murder "victim" and library 
assistant III in the Database Management Team, "although those who did had an enjoyable experience and made new friends in the process. As the "victim," I couldn't participate in solving the crime, but it was fun to watch other staff members uncover the clues." At the conclusion of the game, all materials used in the creation and implementation of the game were cataloged and included in the libraries' special collections unit. ${ }^{15}$

Humor can be incorporated into li-

\section{The negative side of humor, includ- ing sarcasm and sexual or ethnic references, should be left at the door of the workplace before entering.}

brary communications, staff recognition efforts, and staff meetings. Written communication is one area where a little humor can be especially effective. "In workplace writing, many people assume a persona, don a dour attitude and avoid using humor, thinking they may not be taken seriously if they do."16 Incorporating humor in written communications can grab the reader's attention and stimulate interest in the message being conveyed. When seeking an apology or issuing a reprimand, a memo that begins with an amusing anecdote may make the message easier to accept.

Administrative support is essential if formal programs are preferred. Attempting to incorporate humor initiatives without administrative support may succeed only in alienating staff and managers alike, almost guaranteeing a long struggle to implement a meaningful program.

When humor is incorporated into work relationships by management, it is very important to ensure that such activities are appropriate. The negative side of humor, including sarcasm and sexual or ethnic references, should be left at the door of the workplace before entering. Management should be particularly sensitive to inimical behavior and malevolent intent. In such cases, supervisors should and must take quick and suitable action.

\section{Personal Applications}

Individual staff members may employ a variety of tactics to increase personal satisfaction and reduce stress. In its purest form, humor is an intensely personal phenomenon-it is a choice, a conscious decision, an approach to life. Although freedom from stress is not guaranteed, an individual may increase his or her chances of avoiding or lessening its harmful effects by choosing to find the humorous side of an issue or situation. Developing a healthy sense of humor may not prevent or cure disease, but it may enhance an individual's ability to cope more satisfactorily with trying times. But if humor is to be a positive force and not a destructive one, it cannot stem from hostility and anger; rather, it must be the product of a personal philosophy that is grounded in respect for others.

As Joel Goodman of the HUMOR Project recommends, discover the "elf" in yourself. Post your favorite cartoons in your work area, or share humorous stories and anecdotes with colleagues via email. Try arriving at the next staff meeting wearing a clown nose or a funny hat. Locate and make use of "humor allies" imagine how your favorite television sitcom character or cartoon personality would react to the issue at hand. ${ }^{17}$

Concentrate on developing and consistently implementing a positive perspective. When a project does not turn out quite right or a carefully planned service or event is less than successful, look for solutions, not fault. Work toward reacting with amusement rather than anger when a patron or coworker says or does something inappropriate or unkind. Fear and mirth cannot coexist; recognizing and working to overcome destructive thought patterns and finding and appreciating the humorous aspects of experiences and situations is fundamental to "de-stressing" our lives.

Cope with stress through reframing, or gaining control over, perceptions of events and not control over the events themselves. This concept is illustrated by the following story: 
As a young teacher was writing an assignment on the chalk board, she was startled by a sudden noise in her classroom. Unbeknownst to her, the students had all conspired to drop one book onto the floor at exactly 10:14 a.m. At that point the teacher had three options as she turned to face the class. She could have punished the whole class for their outburst, but this could erode the existing classroom rapport. She could have ignored the whole situation, but this could have encouraged the students to think of more pranks to play in the future. Instead, the teacher walked to her desk and dropped one of her own books onto the floor with the following reply: "Sorry, I'm a little bit late!"18

Acknowledge the fact that humor styles and an individual's ability to perceive humor are as diverse as any other personal characteristic. What is hilariously funny to one person may not be at all amusing to another. In addition, the degree to which an individual is either personally involved in or personalizes an event or process may govern his or her ability to appreciate the humor in a situation. ${ }^{19}$ For this reason, the use of humor in certain situations (including crisis situations) must be handled delicately. For example, a young librarian, a new professional, was given a complicated, timeconsuming assignment that demanded the highest standard of accuracy-a bibliographic instruction workbook. The librarian's supervisor stressed the need for an error-free product. Eager to be viewed a success in a new job, the librarian subconsciously linked personal success on the job with the production of a perfect workbook. After working intensely on the project for weeks, errors were detected by the librarian's colleagues after the final product was printed and a "mistake-o-meter" was devised to chart the error rate. Although the humor was sincerely directed at the situ- ation and was not intended to belittle the individual, the librarian who had worked so hard on the workbook, and for whom an error-free product and job success were synonymous, was unable to see the humor.

\section{What is hilariously funny to one person may not be at all amusing to another.}

Humor should be focused on appropriate targets, such as an inanimate object (the copy machine or the new computer system) or personal foibles, not on another individual. Laughing at others is insensitive and divisive; laughing with others builds positive rapport. But it is important to recognize that self-deprecating humor can backfire if overused. ${ }^{20} \mathrm{~A}$ worker who frequently tells stories illustrating his or her tendency to be scatterbrained or disorganized may lead coworkers and supervisors to believe it to be true.

\section{How Many Academic Librarians Does It Take....?}

In these rapidly changing times, humor may be a key to controlling stress, promoting good health, and encouraging positive work relationships. As the literature suggests, people who enjoy their work are more productive and creative, and because they are more satisfied with their jobs, they tend to promote better morale in the workplace. Even if a librarywide program is not workable or feasible, embracing humor on a personal level can be an effective means of improving the work experience.

So how many academic librarians does it take to change a lightbulb? There are many possible answers to this puzzling question, and only you know which is correct in your library, but for academic libraries in general the answer could be eight-seven to form a committee to determine if it really needs changing, and one to change the bulb! 


\section{Notes}

1. Webster's Third New International Dictionary of the English Language Unabridged (Springfield, Mass.: G. and C. Merriam Company), s.v. "humor."

2. William F. Fry, "The Physiologic Effects of Humor, Mirth, and Laughter," JAMA 267, no. 13 (Apr. 1992): 1857-58.

3. James A. Thorson et.al, "Psychological Health and Sense of Humor" Journal of Clinical Psychology 53, no. 6 (Oct. 1997): 605-19.

4. Christiane Humke and Charles E. Schaefer, "Sense of Humor and Creativity," Perceptual and Motor Skills 82 (Apr. 1996): 546.

5. Timothy Eugene Spruill, "Sense of Humor as a Mediator of the Effects of Stress on Physical Health and Psychological Well-being" (Ph.D. diss., Western Michigan Univ., 1992), 110.

6. Brian Richard Humphreys, "A Cheerful Heart Is Good Medicine: The Emotional and Physical Benefits of Humor" (Ph.D. diss., Biola Univ., 1990), 44.

7. Robert Holden, "Enjoyment in Employment: How to Utilize the Power of Laughter, Humour and a Winning Smile at Work," Employee Counseling Today 5, no. 4 (1993): 18-19.

8. Bodil Jones, "I Guess You Had to Be There," Management Review 85, no. 10 (Oct. 1996): 55.

9. Joseph F. McKenna, "The Workplace: But Not So Seriously, Folks," Industry Week 241, no. 14 (July 1992): 20.

10. W. Bradford Swift and Ann T. Swift, "Humor Experts Jazz Up the Workplace." HR Magazine 39, no. 3 (Mar. 1994): 72-75.

11. Joseph F. McKenna, "Lighten Up . . or Else," Managing Office Technology 40, no. 7 (July 1995): 9.

12. C. W. Metcalf and Roma Felible, "Humor: An Antidote for Terminal Professionalism," Industry Week 241, no. 14 (July 1992): 15.

13. Susan B. Whyte, "Stuffy No More: Passion and Humor in the Library," College \& Research Libraries News 3 (Mar. 1996): 138.

14. Roberta L Tipton, "Humor and Work: A Selected Bibliography," Unabashed Librarian, no. 91 (1994): 9. 1988.

15. Michigan State University. Libraries' Murder Mystery Committee. Murder Mystery Game,

16. Wilma Davidson, "Add Humor to Workplace Memos," Personnel Journal 71, no. 6 (June 1992): 67.

17. Henry Alford, “Endpaper, 'Humor Me,'” New York Times Magazine, July 3, 1994, 46.

18. M. Kathleen Unland and Brian Kleiner, "How to Enhance Your Sense of Humor," Agency Sales 25, no. 8 (Aug.1995): 56.

19. Steven M. Sultanoff, "Using of Humor in Crisis Situations," http:// www.humormatters.com/crisis.htm. 74.

20. David J. Abramis, “Humor in Healthy Organizations," HR Magazine, 37, no. 8 (Aug. 1992): 